\title{
ESTUDOS
}

\section{A força das afinidades: estudo sobre a politização do campo educacional brasileiro}

Gilson R. de M. Pereira

Palavras-chave: autonomia universitária; politização; formação de professores; ensino superior.

\section{Resumo}

A partir da análise de artigos publicados em periódicos especializados, a pesquisa investiga as formas assumidas pela politização do campo educacional brasileiro durante os anos de 1978 a 1986. A politização, manifestação de um estado intensamente heterônomo do campo educacional, caracterizou-se, no período, pela aliança ambígua entre educadores e trabalhadores, transfiguração quase irreconhecível das afinidades estruturais entre agentes ocupantes dos pólos dominados, tanto do campo universitário quanto do espaço social geral.
Os produtos culturais devem suas propriedades mais específicas às condições sociais de sua produção e, mais precisamente, à posição do produtor no campo de produção que comanda ao mesmo tempo (e, por mediações diferentes, o interesse expressivo), a forma e a força da censura que lhe é imposta, e a competência que permite satisfazer este interesse nos limites desses constrangimentos.

Bourdieu, 1989, p. 92.

O presente texto visa descrever aspectos dos jogos simbólicos praticados no campo educacional brasileiro a partir da análise da politização ocorrida neste durante os anos de 1978 a 1986. O material empírico submetido a exame são textos publicados em dois periódicos especializados: $A N D E$ (Revista da Associação Nacional de Educação), do $n^{0} 1$, de 1981, ao $n^{0} 11$, de 1986 , e Educação \& Sociedade, do $\mathrm{n}^{0} 1$, de setembro de 1978, ao $\mathrm{n}^{\circ} 24$, de agosto de 1986. Estas revistas foram selecionadas em razão de sua legitimidade e de concentrarem, talvez, os textos mais representativos da politização operada no campo educacional à época. Deu-se preferência ao período mencionado em razão das intensas atividades políticas ocorridas nas universidades - greves e manifestações de professores, estudantes e funcionários -, formando, como se percebia então, um "quadro socioeconômico-político sabidamente difícil” (Aos colegas..., 1983, p. 2). Os textos, por sua vez, foram escolhidos por apresentarem sistematicamente opiniões ou formulações teóricas sobre as tarefas e os objetivos da escola e da universidade, a autonomia das instituições do campo educacional e alianças, proximidades e afastamentos ideológicos dos educadores.

$\mathrm{Na}$ apreensão aqui realizada de aspectos do campo educacional brasileiro, no período especificado, não há nenhuma intenção de "denúncia retrospectiva”, de crítica, nem de alguma forma de "debate póstumo" ou de contabilização de acertos ou erros e de interpretações apropriadas ou não sobre os temas escolhidos. A análise de formulações de educadores brasileiros num passado recente, caracterizadas pela centralidade então conferida à política, sobre os temas anteriormente referidos, pode lançar luz sobre as maneiras pelas quais o 
campo educacional retraduz os conflitos latentes ou abertos de toda a sociedade. Descobrir os processos mediante os quais os campos retraduzem as lutas sociais é uma forma de apreender a autonomia desses, logo, os graus de liberdade usufruídos pelos agentes e, ao mesmo tempo, as coações estruturais invisíveis que pesam sobre eles num determinado período histórico.

Este estudo parte da proposição, aparentemente banalizante, porém desmistificadora, segundo a qual o educacional é um campo como "outro qualquer”: é um espaço estruturado de relações mediante as quais os agentes disputam os capitais específicos em jogo. Assim como o campo político, o econômico, o da alta costura, o literário, o religioso, entre outros, o educacional possui suas próprias normas, valores, interesses, instituições, hierarquias de legitimidade e critérios de divisão social. Está dotado de mecanismos internos por meio dos quais, segundo uma lógica específica, os agentes a ele vinculados obtêm lucros, embora não necessariamente econômicos, sofrem sanções, recebem prêmios, lutam, concorrem, complementam-se, coagem uns aos outros, fazem e desfazem alianças e pactos, duradouros ou não.

É fato que uma ou outra característica das lutas empreendidas no campo adquire tal ou qual saliência a partir das pressões conjunturais. No período abordado, sabese quais foram: a luta contra a ditadura militar, pela anistia e por liberdades democráticas, a transição democrática nos anos 80, a alta inflacionária, os movimentos sindicais do período, a irrupção de novos agentes coletivos na cena política, além das esperanças suscitadas pelas revoluções centro-americanas. Porém, a politização é inteligível não pela "relação dialética da educação com a totalidade social”, redução ao contexto preconizada pelo marxismo, mas a partir da análise da estrutura objetiva - campo educacional - formada por agentes e instituições, simultaneamente parceiros e adversários, dos móveis construídos e disputados e das estratégias acionadas. Em vista disso, os autores, cujos trabalhos são a seguir mencionados como evidência da politização ocorrida no campo educacional no período, devem ser considerados não como indivíduos empíricos, mas como "indivíduos epistêmicos" (cf. Bourdieu, 1992, p. 34-36) cujas tomadas de posição, simultaneamente teóricas e práticas, pedagógicas e políticas, correspondem a posições objetivas desse espaço de produção simbólica.

\section{A politização do espaço acadêmico}

É possível mostrar que, durante toda a década de 80, diversas áreas acadêmicas no Brasil passaram por fases de politização um tanto intensas, processo iniciado em meados dos anos 70, e é interessante constatar que mesmo áreas altamente protegidas, como a da arquitetura erudita, também passaram, quase na mesma época, por processos de politização. Exemplar disso é a disseminação do uso do cimento aparente nas construções como forma de denúncia, tanto da exploração do trabalhador quanto das "formas de compromisso do arquiteto com a dominação de classe”. Na Faculdade de Arquitetura e Urbanismo da USP "tornouse habitual, ao invés de arquitetura e urbanismo, discutir-se o caráter 'produtivo' ou 'improdutivo' do trabalho intelectual, ou a distinção entre 'valor de uso' e 'valor de troca', ou, ainda, a natureza classista do projeto arquitetônico” (Durand, 1989, p. 274).

A discussão sobre a "natureza classista" das profissões e instituições universitárias fez-se presente em quase todas as áreas do campo acadêmico, nas décadas de 70 e 80, e tanto mais intensamente quanto mais distante do pólo dominante encontrava-se a área. De fato, a politização parece ter sido mais forte nas ciências sociais que nas exatas, mais presente nas ciências exatas que em Direito e Medicina, mais intensa na sociologia que na economia e mais militante na Educação que nas Ciências Sociais, etc. Se a politização pode ser identificada em todas essas áreas (ver as discussões sobre o direito alternativo, na área jurídica, sobre a socialização da saúde pública ou a medicina popular, na área médica, as reuniões da SBPC em fins dos anos 70, cujos pontos altos foram as intervenções não de cientistas, mas de celebridades políticas da oposição, ou, ainda, as discussões sobre a inserção do serviço social na luta de classes, entre outras), cada uma delas, porém, adquiriu características próprias de acordo com o grau de autonomia da área e, portanto, em razão de sua capacidade de refratar os conflitos externos. Por exemplo, na já mencionada arquitetura erudita, a politização parece ter cumprido 
a função de "ocultar o desgaste da ortodoxia que desde 1967/1968 estaria a mostrar sinais de exaustão e amaneiramento" (Durand, 1989, p. 259).

À medida que se desce nas hierarquias funcionais e nas escalas de crédito simbólico, mais os móveis externos e os termos das lutas sociais aparentam exprimirse diretamente, sem mediações, sem eufemismos, sem a transfiguração proporcionada pela estrutura do campo acadêmico. Pois são justamente nos patamares mais inferiores, os dos servidores das universidades, como também os dos professores ocupantes dos postos culturalmente dominados (classificados, segundo as taxionomias em voga, de "baixo-clero", "improdutivos"), que se encontram os agentes menos aderentes à sutileza dos jogos impostos pela doxa dos campos simbólicos e mais inclinados a expressar imediatamente os conflitos abertos ou latentes de toda a sociedade. Menos por ingenuidade e mais por não se sentirem obrigados à economia de cinismo, mais por déficit de cumplicidade que por cálculo consciente, esses agentes, sobretudo seus representantes sindicais, e dadas as oportunidades propiciadas pela politização das universidades, não conseguiram ocultar os interesses da "revanche contra os que dominam o mundo intelectual” (Bourdieu, 2000, p. 106).

Lugares exemplares dessas revanches verbais foram as assembléias, debates e encontros realizados por entidades corporativas no período. Convidado a participar de um desses debates, promovido por uma entidade nacional de servidores universitários, José Arthur Giannotti (1986, p. 86) resume assim a experiência:

\begin{abstract}
Fiz minha exposição martelando o tema: na universidade, quem sabe mais deve mandar mais. Fui argüido por um argumento dos mais finos: no final das contas, para a nova universidade, vale todo e qualquer saber ou somente aquele que sirva para a libertação das classes trabalhadoras brasileiras? E no calor da discussão um representante não teve dúvida em afirmar peremptoriamente: uma universidade vinculada aos interesses dos trabalhadores não pode permitir que nela sejam estudadas teorias que ensinam como estes são escravizados, como as teorias dum tal Talcott Parsons.
\end{abstract}

Toda a ambigüidade da politização do campo educacional pode ser apreendida quando se observa a semelhança entre as demandas referidas no excerto acima e as dos agentes politizados do campo educacional. A reivindicação de uma escola ou universidade a serviço dos interesses dos trabalhadores estava condenada a estratégias heterônomas ("ampliar os espaços universitários para as contradições”) e, por conseguinte, a contribuir objetivamente para a redução da autonomia do campo e dos graus de liberdade usufruídos pelos educadores. Efetivamente, o curto-circuito entre conhecimento e demandas políticas transforma o primeiro em doutrina ("o saber a serviço de") e isso contribui para despojar a escola e a universidade das características mais flagrantes de arenas, um tanto autônomas, de produção cultural. A defesa de uma escola a serviço dos explorados parece configurar, e seguindo lógicas semelhantes, o oposto imediato das "pressões dos detentores do poder econômico em favor de um ensino subordinado às suas exigências técnicas e, sobretudo, sociais, isto é, ético-políticas" (Bourdieu, 1989, p. 231).

É bastante promissora a hipótese segundo a qual a coincidência de demandas entre educadores e trabalhadores, ou a aproximação de educadores com trabalhadores ("ligação com os de baixo"), deve-se à posição ocupada pela área da educação no espaço acadêmico. Ocupando posições homólogas às dos trabalhadores, os educadores apresentam afinidades estruturais com aqueles, ou seja, ambas as posições - educadores no espaço simbólico, trabalhadores no espaço social geral - caracterizam-se menos por nivelamento salarial ou por eventual perda de controle do "processo e do produto de seu trabalho", ou ainda pela passagem do "trabalho autônomo ao trabalho alienado”, senão pelo fato de serem opções profissionais que implicam a "perda dos atributos simbólicos de dominação" (Miceli, 1977), inclinando-os a alianças tácitas ou explícitas:

O professor vai se tornando força de trabalho. [...] os professores [...] poderão começar a incorporar-se com os "de baixo" e oferecendo sua contribuição maior naquilo que lhes é específico: a produção de conhecimentos. [...] A partir daí é possível sua função de "intelectual" que busque conscientemente ampliar os espaços universitários para as contradições que perpassam a universidade, exatamente porque sua ligação com os "de baixo" começa a se definir mais a nível de classe (A universidade..., 1981, p. 28). 
A força das afinidades estruturais, de modo algum eletivas, entre educadores e trabalhadores, coage os primeiros a pôr sua autonomia correlativamente à dos segundos: "Autonomia das instituições escolares, inclusive universidade, ante os poderes, autonomia dos assalariados em se auto-organizarem a partir de seus locais de trabalho (fábrica, escola, hospital) sem tutela de grupos, partidos ou burocracia" (A luta..., 1982, p. 4).

Se nos postos mais baixos das escalas funcionais e das hierarquias de crédito simbólico encontram-se os agentes mais inclinados às demandas heterônomas, à politização, às vezes à dispensa de eufemismos ("Nós educadores seremos obrigados a nos definir por uma escola a serviço de uma ou outra classe", Arroyo, 1980, p. 14; "Porque toda cultura, toda ciência é uma cultura e uma ciência que atende aos interesses de uma classe", Gadotti, 1978, p. 13), em contrapartida, quanto mais se vai ao pólo dominante do campo acadêmico, ocupado tanto por agentes mais ricos nos capitais específicos (pelos critérios de classificação em vigor, as autoridades, os "notáveis", "mandarins"), quanto pelas instituições posicionadas no topo das legitimidades, mais as demandas são autônomas, puras, ou seja, não imediatamente vinculadas aos constrangimentos externos e, portanto, mais os agentes são inclinados a valorizar a economia específica do campo. Em razão disso, tendem a estratégias de conservação das relações de força, que são igualmente estratégias de manutenção dos critérios de classificação dominantes (cf. Bourdieu, 1997). São também os agentes mais voltados ao uso de eufemismos para designar móveis externos, até o ponto de estes parecerem às vezes praticamente irreconhecíveis.

\section{Temas politizados}

Um campo encontra-se politizado quando, além de aberto às demandas do campo político, o princípio político de visão e divisão do mundo, ou princípio propriamente político de escolha, sobrepõe-se a todos os demais (cf. Bourdieu, 1992, p. 243). Não é, portanto, apenas por uma concessão à lógica do pensamento classificatório que, no campo educacional do período, à pedagogia, à escola, à educação adiciona-se o adjetivo "político"
("A educação sempre foi política. O que precisamos é ter clareza do projeto político que ela defende, politizando-a”, Gadotti, 1981, p. 13), mas, sobretudo, em razão da "aplicação generalizada e sistemática de critérios propriamente políticos ao conjunto dos problemas", com o propósito de submeter a lógica das coisas "ao princípio explícito e objetivo de suas opiniões políticas" (Bourdieu, 1992, p. 244).

Os textos examinados revelam cinco temas mediante os quais é possível apreender as modalidades de inserção do princípio propriamente político de escolha no campo educacional brasileiro. A reiteração com que são abordados nos periódicos e a legitimidade dos autores permite constatar o elevado grau de consenso em torno de sua relevância. Os temas são: a) a escola pública "que convém à maioria"; b) a função política da educação; c) a "pedagogia revolucionária"; d) a "revolução"; e) a identificação entre educadores e trabalhadores.

Uma vez submetidos à análise, esses temas, tais como aparecem nos periódicos, possibilitam, como já se disse, apreender as características da politização do campo no período, bem como lançam luz sobre os lances ativados pelos agentes, na disputa pelos capitais em jogo, em suas estratégias de distinção e rentabilização simbólica. Conquanto não seja objeto deste estudo, mesmo as disciplinas aparentemente mais neutras também sofreram abordagens politizantes. É suficiente recensear o compromisso da didática com a transformação social (Candau, 1983) e o compromisso político do professor de Matemática (Duarte, 1985).

\section{Estratégias de rentabilização simbólica}

Um dos aspectos mais marcantes da politização do campo educacional no período é a utilização de estratégias de dupla rentabilização simbólica: às vias da legitimação conferida pelo saber em geral, ou pela ciência ("Dentro desta perspectiva científica - a Dialética ou é científica ou não é nada”, Gadotti, 1979, p. 7; "Não se afastar e isolar da luta coletiva das camadas populares e dos trabalhadores do ensino, mas somar com o que ele tem de específico, sua ciência e seu saber na ofensiva comum contra a divisão do trabalho na escola e na produção", Arroyo, 1980, p. 22), 
adicionava-se a legitimação propriamente política conferida pela pregação democrática e revolucionária ("pedagogia revolucionária”, "educação e luta de classes”, "alfabetização revolucionária”, "educação transformadora”). Praticado no Brasil pelos que reivindicavam o marxismo, lugar geométrico na produção acadêmica destinado a garantir a dupla ilusão de absolutismo político e epistemológico (cf. Bourdieu, 2000), ou seja, a utopia da visão soberana e definitiva sobre o conhecimento e a prática política, e bastante flexível para preconizar e justificar estratégias de alianças entre educadores e trabalhadores, respectivamente, como já se disse, os homólogos do campo acadêmico e da produção material, o "cientificismo populista” foi, por suas virtudes de ajustar duas ilusões bem fundadas - a do ponto de vista absoluto na ciência, o materialismo histórico e dialético, e a do ponto de vista absoluto no social, o proletariado -, a condição necessária à fatura simbólica nas lutas pedagógicas e políticas do campo educacional no período.

Se a dupla rentabilização acima referida foi possível graças ao ajuste das ilusões dos absolutos político e epistemológico, foi operacionalizada pela inserção teórica da escola e da universidade na luta de classes e pela descoberta igualmente teórica do potencial revolucionário das instituições educacionais. A ativação da força transformadora da escola parece caracterizar a retomada de uma característica do estilo de pensamento pedagógico brasileiro, inclinado, como observou Luiz Pereira, a enfatizar o dinamismo da instituição escolar em relação ao todo social. Em época de politização e militância, isso conduz à legitimação de teorias portadoras de algum esquema "de interferência na realidade no qual o papel dinâmico das modificações nas instituições escolares seria dos mais preponderantes" (Pereira, 1967 , p. 160). No período aqui abordado, esse estilo exacerbar-se-ia até a pregação das potencialidades transformadoras do trabalho pedagógico e da "pedagogia revolucionária” ("que identifica as propostas burguesas como elementos de recomposição de mecanismos hegemônicos e se dispõe a lutar concretamente contra a recomposição desses mecanismos de hegemonia, no sentido de abrir espaço para as forças populares", Saviani, 1981a, p. 33).
A inserção da escola e da universidade na luta de classes foi, na época, uma operação considerada possível e até empiricamente evidente. Afinal, dizia-se, a escola "sempre foi classista", e a educação sempre desempenhou uma função política. Trazer esses impensados à tona, ocultados pela "má consciência burguesa", era, como também se dizia no período, realizar "um ato filosófico" tão mais importante quanto mais politicamente eficaz no processo de "libertação dos oprimidos". A força do enunciado, como se sabe, decorre de sua legitimidade (quem diz "luta de classes", de um ponto de vista legítimo, certamente contribui para fazê-la existir) e, num campo politizado, a legitimidade ganha força, num processo circular de ampliação crescente, com a força política do enunciado.

A escola mantém uma relação dinâmica com a realidade social, ela possibilita a luta por melhores condições de vida, a formação de dirigentes políticos representantes das camadas populares, desmistifica os conteúdos das matérias, substitui modelos sociais e éticos por outros adequados a um novo projeto de sociedade, ou seja, ela é uma ameaça à ordem estabelecida (Libâneo, 1982, p. 42).

Toda atividade humana na medida em que é social é política, a dimensão do político não é privilégio do Estado nem dos partidos políticos. O mesmo ocorre com a educação: ela pode servir à política da classe dominante ou dos explorados. [...] No processo social onde as forças populares têm hegemonia, a ação educativa é uma parte da luta mais ampla entre as classes sociais pela hegemonia. Por isso é inconcebível separar a prática educativa da prática organizatória e da prática política. Da mesma maneira que a insurreição popular na Nicarágua foi o ponto de partida pedagógico, a resistência de professores, funcionários e alunos à invsão da Unicamp pelas máfias burocráticas se constitui no ponto de partida para pensar melhor o que significa prática, conscientização e participação. [...] a luta é a grande educadora e a organização surgida da luta é a grande escola (Educação..., 1981, p. 3)

Em suas estratégias de rentabilização e impelidos pela lógica concorrencial do campo, os agentes politizados imergiram nos critérios propriamente políticos de escolha e com isso puderam realizar nas discussões pedagógicas o sonho da "politização total”. E suficiente reter mais alguns exemplos: 
“a escola está impregnada de ponta a ponta pelo aspecto político. [...] a ver o sentido político da escola mesmo ali onde ele aparentemente não existiria, onde ele está oculto sob a aparência do estritamente técnico" (Saviani, 1983, p. 116). Para exceder as proposições da pedagogia revolucionária defendida por Dermeval Saviani, foi preciso criar a categoria do "educador-político", cuja missão "é defender a mudança social a nível da relação de propriedade, erguendo e praticando sem rodeios a bandeira pedagógica do máximo de educação para o trabalhador [...] é engajar-se nas lutas para subverter a atual prática político-econômica nacional" (Nosella, 1986, p. 132). Sempre mais à esquerda, provavelmente fruto intelectual das exigências crescentemente arbitrárias das leis de concorrência de um campo politizado, cujo domínio parecia cada vez mais distante, esse educador, de prontidão, em razão de sua libido revolucionária, para atuar em todas as frentes, "sabe que a televisão deve ser literalmente tomada de assalto pelos trabalhadores" (Nosella, 1986, p. 134).

Seria talvez preciso exumar o breve debate que, a propósito da "pedagogia nova”, uniu e opôs três autores na disputa pelo capital simbólico representado pela interpretação autorizada do marxismo (cf. Saviani, 1981a, 1982; Ghiraldelli Júnior, 1986; Nosela, 1986), para revelar, pela análise sociológica do discurso, as posições e tomadas de posição dos agentes politizados no período e as disposições acadêmicas correspondentes - afirmação indignada: "É preciso dizer um basta!"; marcações de autoridade: "Lenin defendeu", "Gramsci expôs, perfeitamente"; restauração da ortodoxia: "Na verdade, o marxismo não se dobrou"; ritual de deferência: "Saviani, com seu afiadíssimo bisturi lógico, distingue e subdistingue magistralmente"; desvio do capital: "Comparando as observações que Saviani e Gramsci fazem sobre a velha escola"; postura doutoral: "Não adianta nada eu ficar sempre repetindo o refrão"; angústia do desvio teórico: "O confronto do texto de Gramsci com o de Saviani suscita algumas dúvidas". No mercado lingüístico do campo educacional do período, esses procedimentos retóricos eram trunfos distintivos, taxa de entrada paga para figurar, de direito, no círculo dos guardiães do comentário legítimo da teoria marxista.
Representantes políticos, conscientização, desmistificação de conteúdos, luta, hegemonia, sentido político, novo projeto de sociedade, mudanças radicais, ameaça à ordem, noções inscritas num cenário discursivo marcado pela politização, revelam as bandeiras que terminam, e sem quebra de seu desenvolvimento lógico, por negar, sob a mística da revolução, o próprio trabalho pedagógico, forma absoluta de imposição simbólica dos princípios propriamente políticos de visão e divisão do mundo.

Reivindicar ensino público e gratuito [...] é lutar por mudanças muito mais radicais, políticas e econômicas. É muito mais que definir conteúdos mais ou menos importantes ou a melhor forma de avaliar. É dar aos alunos instrumentos também de luta, e não só de pensar. Caso contrário cai-se no jogo verbal que a democracia capitalista alimenta (Almeida, 1983, p. 137).

Um depoimento da época sintetiza as disposições dos educadores mais politizados:

Muitos colegas defendem uma tese que dá mais ou menos no seguinte: não à escola, principalmente à escola pública, por ser um aparelho do poder. É preciso fazer "a revolução" lá fora para se conseguir trazer a "revolução para dentro da escola" (Beisiegel, 1981, p. 55).

A função política da educação, como já se disse, era um móvel de lutas no campo politizado do período ("a função política da educação é freqüentemente reduzida ao momento do ato de 'dizer'. Tornase necessário, portanto, rever a própria função política da técnica do discurso para que esta técnica não venha negar o conteúdo do discurso e sua validade na prática educativa”, Oliveira, 1983, p. 29), correlativo à crítica à neutralidade das instituições de ensino ("o silenciar da dimensão política”). Se a pretensão soberana à objetividade ("encastelamento"), isto é, se o direito suposto à ausência de ponto de vista socialmente situado ("assepsia ideológica"), realpolitik distintiva dos "mandarins" hostis às "representações interessadas e parciais" (Bourdieu, 1997, p. 40) dos agentes politizados, dá razão aos críticos, em geral situados nas posições mais baixas das hierarquias simbólicas, estes terminam, pela incorporação da politização total, por recusar tanto a distância objetivante enredada na concorrência 
científica quanto os pontos de vista associados ao pertencimento a um universo simbólico não imediatamente sujeito às sanções econômicas e políticas ("As elites são sempre servidas pela universidade"; "A camada dominante encarrega a universidade de prover suas necessidades").

Outra estratégia de ganho simbólico, garantia quase certa de sagração acadêmica na época, é a defesa da comunicação dos produtores intelectuais com o povo ("Sem o jargão academicista, estéril, a universidade, mediante professores e alunos, oferece um serviço de apoio às organizações sociais de massa, democratizando a produção teórica”, A universidade..., 1981, p. 28) e a ligação da universidade com os "interesses populares”, forma de resgate do que era então considerada a missão democrática da "nova" universidade, ou seja, a contestação da "subordinação aos interesses do capital" e a defesa dos "interesses do trabalho". A nova universidade, comprometida com os interesses populares, é a correspondente, no terceiro grau, da escola pública "que convém à maioria", contrahegemônica, inserida "no processo mais amplo de construção de uma nova sociedade" (Saviani, 1981a, p. 33).

Essa estratégia garantia aos agentes politizados lugar entre os produtores ("a produção de conhecimento e sua transmissão desde um outro ponto de vista”, A universidade..., 1981, p. 28), com todos os créditos daí decorrentes, e simultaneamente os rendimentos simbólicos advindos dos posicionamentos políticos implicados na defesa dos “de baixo” ("Qualquer estratégia particularista e elitista que evite se misturar com os de baixo [...] é fazer o jogo do sistema”, Arroyo, 1980, p. 21).

\section{Intelectual orgânico}

Isso certamente envolvia o ajuste do educador aos interesses não das elites, mas dos trabalhadores. A transformação do educador em intelectual orgânico, "ideologia profissional dos produtores intelectuais de aparelho" (Bourdieu, 2000, p. 105), é a verdadeira magia social do período, decorrência do ajuste quase perfeito entre o cientificismo populista, sobretudo em sua versão gramsciana, e as afinidades estruturais dos agentes do campo educacional. A sagração do educador na ordem do intelectual orgânico configura-se como duplicação da legitimidade: além da conferida pelo Estado (o diploma, os cargos nas instituições acadêmicas tanto públicas quanto privadas, a garantia estatutária de enunciar as formas de classificação, de visão e divisão do mundo), os agentes politizados transcreviam para seus pontos de vista a ambição de legitimidade suplementar garantida pela monopolização (na época, chamada de "hegemonia”) do político:

Na rearticulação que se há de estabelecer, o supervisor, ponto crucial da relação hegemônica, haverá de se transformar de funcionário do Estado em intelectual orgânico das massas docentes. Se e quando isso ocorrer, a supervisão escolar terá não apenas encontrado sua viabilidade, mas, principalmente, assegurado sua legitimidade (Silva Junior, 1982, p. 40).

Dependente de um tipo muito particular, o intelectual orgânico encontra em sua dependência relativa ao Estado a proteção aos constrangimentos do mercado (cf. Bourdieu, 1997, p. 48). Tipo ideal de toda uma intelectualidade das camadas médias, porta-voz autorizado "que faz crescer a força de sua autoridade convocando o grupo a se mobilizar e mobilizando-o efetivamente" (Bourdieu, 2000, p. 84), o intelectual orgânico sintetiza o paradoxo do intelectual funcionário, mantido pelo Estado e cuja liberdade é voltada contra este.

\section{Estratégias de reviravolta das posições acadêmicas}

Essas estratégias de dupla rentabilização desdobravam-se, além disso, numa estratégia de reviravolta das posições do campo acadêmico: esperançosos de contabilizar capitais extra-acadêmicos, sobretudo os reconhecidos pelo campo político, e, por meio destes, legitimar suas posições e escalada de distinção acadêmica, os agentes radicalizados do campo investiram fortemente na aliança com os "de baixo", única via de construir uma peculiar forma de autonomia universitária, mais condizente com suas disposições contestatárias e seus trunfos simbólicos. Essa autonomia, que recomendava a "ampla participação dos corpos docente e discente e dos representantes dos diferentes grupos sociais no próprio processo de repensar e refletir a universidade" (A universidade..., 1981, p. 29), isto é, autonomia aberta às demandas dos diferentes grupos de pressão e interesses, era, 
afinal, o eufemismo utilizado para ocultar os propósitos de reviravolta nas posições acadêmicas:

[...] a idéia de autonomia não se restringe à simples garantia de autonomia financeira, administrativa e acadêmica para que um grupo de "notáveis", mais comprometidos com as classes dominantes, conduza os destinos de cada universidade. [...] Enfatizamos que não teria mais sentido garantir "autonomia" para um pequeno grupo no poder em cada instituição, não identificado com os problemas dos diferentes grupos sociais (A universidade..., 1981, p. 28-29).

Nas lutas travadas no campo durante o período, a incoerência do excerto acima é apenas aparente (quando se defende a presença de representantes dos "diferentes grupos sociais" na instituição e, ao mesmo tempo, se discrimina os "notáveis" comprometidos com as classes dominantes). O que há de implícito é a adesão a princípios heterônomos, a condenação da não identificação com as lutas sociais. Num campo politizado, o suscetível de crítica é não tomar partido. A crítica é endereçada, portanto, ao intelectual acadêmico, autônomo e certamente dotado de elevados créditos simbólicos ("notáveis"), não diretamente comprometido com as responsabilidades decorrentes da inserção imediata nos conflitos sociais. Na luta pela reviravolta do estado de forças do campo acadêmico, provavelmente o capital possuído pelos agentes culturalmente dominados era justamente a identificação com as lutas populares. Moeda política convertível em trunfo acadêmico. Trazer a universidade para o centro dessas lutas era valorizar seus capitais e, por conseqüência, rentabilizar suas posições e tomadas de posição.

No campo educacional politizado, preconizava-se, portanto, a autonomia da universidade como sinônimo de abertura aos interesses de toda a sociedade, de franquia a todas as demandas sociais:

A universidade é chamada a ser o palco de discussões sobre nossa sociedade, mas não em termos puramente teóricos e abstratos. [...] a universidade precisa ser transformada, precisa assumir forma nova, novo modo de existir. Se ela emerge de uma sociedade que precisa ser transformada, não deve visar prioritariamente a transmissão de um saber constituído [...]. Desse ponto de vista, é um lugar político, pois o processo de elaboração científica também implica numa opção política (Fávero, 1983, p. 44-45).

[...] Não estamos propondo que a universidade deva abandonar os interesses da burguesia [...] o que estamos propondo é que a universidade assuma o papel de instituição de toda a sociedade e não apenas da burguesia, permitindo que outras questões sejam igualmente freqüentadas no seu fazer (Rodrigues, 1982, p. 24).

A universidade é entendida como [...] uma instância fundamental, cujo controle é disputado por aqueles grupos sociais (frações de classe) que pretendem impor suas próprias concepções sobre a sociedade (Veiga, 1982, p. 25).

O direito de tornar legítimo o ilegítimo ("não em termos puramente teóricos e abstratos"; "que outras questões sejam freqüentadas no seu fazer"; "suas próprias concepções de sociedade") é a sutileza que dissimula os propósitos de reviravolta nas posições do campo, com o conseqüente direito de instituir ("forma nova"), pela força do poder simbólico acrescido do poder político, o papel da universidade ("um lugar político”).

Outro elemento integrante da luta pela reviravolta das posições do campo e dos critérios de classificação vigentes no período é a luta pela definição das funções da universidade, tema relacionado ao da autonomia e, em particular, ao das demandas sociais que a universidade supostamente deveria atender. Pela lógica da concorrência travada no campo, combateu-se a pesquisa desinteressada e não imediatamente vinculada a problemas sociais (supostos definidos externamente à instituição, ou seja, "pela sociedade civil organizada”). A prevenção relativa a uma certa irresponsabilidade social da pesquisa pura (ciência pela ciência) é homóloga à prevalência da funcionalidade sobre a forma nos critérios de apreciação artística: arte proletária ou arte comprometida em vez de arte pela arte, formas de classificação mais pertinentes aos agentes ocupantes das posições culturalmente dominadas, inclinados a ver na verdade da arte a sua funcionalidade decorativa ou política.

[a universidade] se dedica, por vezes, a pesquisas não muito relevantes socialmente e a um ensino também não muito relevante socialmente. [...] Nesse caso ela pode 
ter a tendência a se preocupar com problemas que não são os problemas da sociedade na qual está inserida. [...] em que medida ele [o pesquisador] está contribuindo para resolver problemas da sociedade na qual sua universidade está inserida, sociedade essa que financia essa pesquisa? [...] Com efeito, é a sociedade que vai colocar os problemas; é o contato com os problemas efetivos da sociedade que vai permitir à universidade transformar os objetos de suas pesquisas em algo relevante para a sociedade (Saviani, 1981b, p. 63-67).

A adesão a princípios heterônomos fica sugerida nos textos ao se observar a subestimação da relevância científica da pesquisa, quando se pretendia, então, hierarquizá-la a partir de critérios extraídos de taxionomias estranhas à lógica da pesquisa científica, "relevância social" designada como atributo da sociedade, de acordo com as recomendações mais legítimas do campo à época. Essa adesão também fica explicitada quando, ao se abordar a questão da "devolução à sociedade" dos privilégios decorrentes da educação superior, enfrenta-se o dilema de saber se a devolução, na forma de serviços prestados à comunidade, pretende favorecer os grupos dominantes ou os dominados, e, no caso da opção pelos últimos, "possibilitar que a sociedade se transforme na direção de relações sociais mais justas" (Saviani, 1981b, p. 71).

O discurso sobre as demandas sociais e a contrapartida aos privilégios decorrentes do financiamento da pesquisa e do ensino universitário com verbas públicas é um recurso para assegurar posições de força simbólica "nas lutas internas pelo monopólio da definição legítima da prática científica” (Bourdieu, 1997, p. 40). A legitimidade suplementar é adquirida ao dizer de direito o que é socialmente relevante ou não na pesquisa. $\mathrm{O}$ discurso sobre a relevância social da pesquisa é o correspondente, no âmbito político, das lições canônicas de metodologia da ciência, nas quais cientistas sem obra pontificam sobre o que se deve ou não fazer e a "maneira científica” de fazer ciência.

Essa forma de pôr a universidade a serviço da sociedade é certamente indício de heteronomia e, portanto, de "concorrência imperfeita", visto que, quanto mais heterônomo o campo, mais os agentes buscam nos poderes externos (a "população organizada”, comunidades, partidos, igrejas, imprensa, empresas, geralmente englobados sob o termo genérico de sociedade civil, mas também órgãos de governos e instituições estatais) o princípio de legitimidade para as lutas políticas travadas em seu interior (cf. Bourdieu, 1997). Além disso, na concorrência imperfeita, os aliciamentos externos são mais sedutores em razão da legitimidade dos critérios de visão e divisão advindos de outros campos. Do religioso, por exemplo, com seu etos sacerdotal ou sua moral carismática de possuir uma missão, “devolver, retribuir”, ou do campo político, como a legitimidade conferida à defesa do povo, das classes trabalhadoras, absolutos políticos que, pela lógica concorrencial do campo no período, transmutam-se em absolutos epistêmicos, intocáveis teóricos, pois não alcançados pelas censuras cruzadas do campo, visto que, nos campos politizados, a crítica às proposições dos porta-vozes do povo corre sempre o risco de ser interpretada como crítica ao próprio povo, certamente com o conseqüente risco da máxima suspeição, qual seja, a de ser "antipopular”, cujo perigo, no limite, é o da excomunhão.

\section{Conclusão}

A partir de meados da década de 80, as disposições contestatárias impulsionadas pela politização vão mudando paulatinamente, certamente moldadas por outra configuração das forças analíticas do campo educacional, menos inclinadas às críticas politizadas e mais propensas a realçar a dimensão propositiva das formulações. Educadores politizados já terão passado pelas primeiras experiências com a gestão da educação pública desde o golpe militar de 1964 (ver a apresentação de propostas das Secretarias de Educação do Estado de Minas Gerais e do Município de São Paulo, cf. $A N D E$, n. 11, 1986) e as teorias então candidatas à imposição dos arbitrários mais legítimos começam a experimentar as primeiras responsabilidades advindas da legitimidade. A revolução e as classes trabalhadoras cedem lugar à democracia e à cidadania. Nessa chamada ao realismo, nesse ajuste das expectativas às chances, falar-se-á de "democracia possível”, direitos sociais, resistência. Se a educação ainda continua a desempenhar uma função crítica e transformadora, a escola, nos anos 
imediatamente anteriores a Constituinte, já recebe interpretações que a põem "a serviço do interesse público”. À escola, que, como visto, era uma "ameaça à ordem estabelecida”, atribui-se agora a responsabilidade de contribuir para a "humanização do homem em todas as suas dimensões" e cujo papel é o da "divulgação da cultura a todos" (Libâneo, 1986, p. 6).

A politização do campo educacional e a aliança entre educadores e trabalhadores, assim como as formas eruditas assumidas, como a do mencionado "cientificismo populista”, inteligíveis a partir do estado do campo no período, podem ser descritas como reação tanto à posição dominada do educador no quadro das carreiras acadêmicas, quanto aos arbitrários culturais dominantes no estado anterior do campo (pelas taxionomias em voga no período, tecnicismo, psicologismo, pedagogia nova ou tradicional, entre outros). Ocupando posição no campo acadêmico, homóloga à dos trabalhadores no espaço social geral, os educadores e seus porta-vozes autorizados investiram sistematicamente na aliança com seus afins, os "de baixo”, recurso valioso na tentativa de reviravolta das posições acadêmicas, visto que configura estratégia de dupla rentabilização simbólica (ao diploma e ao cargo adiciona-se a credibilidade política conferida aos que se batem pelo povo). Aliança ambígua, pois condenada a estratégias heterônomas, mais inclinadas a angariar nos poderes externos os princípios de legitimidade para as lutas empreendidas, portanto, a reduzir a diferenciação e autonomização do espaço profissional dos educadores.

\section{Referências bibliográficas}

ALMEIDA, M. J. de. O ensino público não é nem público nem gratuito. Educação $\mathcal{E}$ Sociedade, São Paulo, n. 16, p. 133-137, dez. 1983.

ARROYO, M. G. Operários e educadores se identificam: que rumos tomará a educação brasileira? Educação \& Sociedade, São Paulo, n. 5, p. 5-23, jan. 1980.

BEISIEGEL, C. de R. Relações entre a quantidade e a qualidade no ensino comum. ANDE, São Paulo, n. 1, p. 49-56, 1981.

BOURDIEU, P. A Ontologia política de Martin Heidegger. Campinas, SP: Papirus, 1989a. . Homo academicus. Paris: Minuit, 1992.

. La noblesse d'état: grandes écoles et esprit de corps. Paris: Minuit, 1989b.

. Les usages sociaux de la science: pour une sociologie clinique du champ scientifique. Paris: Editions INRA, 1997.

Propos sur le champ politique. Lyon: Presses Universitaires de Lyon, 2000.

CANDAU, V. M. A didática e a formação de educadores: a busca da relevância. ANDE, São Paulo, n. 6, p. 37-41, 1983.

AOS COLEGAS educadores. ANDE, São Paulo, n. 6, p. 2-3, 1983.

DUARTE, N. O compromisso político do educador no ensino da matemática. ANDE, São Paulo, n. 9, p. 51-57, 1985.

DURAND, J. C. Arte, privilégio e distinção: artes plásticas, Arquitetura e classe dirigente no Brasil, 1855/1985. São Paulo: Perspectiva, 1989.

EDUCAÇÃO e política. Educação \& Sociedade, São Paulo, n. 10, p. 3-4, set. 1981.

FÁVERO, M. de L. de A. Universidade, poder e participação. Educação \& Sociedade, São Paulo, n. 16, p. 42-61, dez. 1983. 
GADOTTI, M. Ação pedagógica e prática social. Educação \& Sociedade, São Paulo, n. 4, p. 5-14, set. 1979.

Concepção dialética da educação e educação brasileira contemporânea. Educação \& Sociedade, São Paulo, n. 8, p. 5-32, jan. 1981.

. Revisão crítica do papel do pedagogo na atual sociedade brasileira: introdução a uma pedagogia do conflito. Educação \& Sociedade, São Paulo, n. 1, p. 5-16, set. 1978.

GIANNOTTI, J. A. A universidade em ritmo de barbárie. 2. ed. São Paulo: Brasiliense, 1986.

GHIRALDELLI JÚNIOR, P. A vara teimosa: debatendo com Paolo Nosella. Educação \& Sociedade, São Paulo, n. 24, p. 116-145, ago. 1986.

LIBÂNEO, J. C. Saber, saber ser, saber fazer: o conteúdo do fazer pedagógico. ANDE, São Paulo, n. 4, p. 40-44, 1982. $\overline{5-13,1} 986$.

Os conteúdos escolares e sua dimensão crítico-social. ANDE, São Paulo, n. 11, p.

A LUTA pela autonomia contra a exclusão. Educação \& Sociedade, São Paulo, n. 11, p. 34, jan. 1982.

MICELI, S. Poder, sexo e letras na República Velha: estudo clínico dos anatolianos. São Paulo: Perspectiva, 1977.

NOSELLA, P. Educação tradicional e educação moderna: debatendo com Saviani. Educação \& Sociedade, São Paulo, n. 23, p. 106-135, abr. 1986.

OLIVEIRA, B. Aprendendo a ser educador técnico + político. Educação \& Sociedade, São Paulo, n. 15, p. 20-31, ago. 1983.

PEREIRA, L. A escola numa área metropolitana: crise e racionalização de uma empresa pública de serviços. São Paulo: Pioneira, 1967.

RODRIGUES, N. Autonomia e universidade: uma questão política. Educação \& Sociedade, São Paulo, n. 11, p. 5-24, jan. 1982.

SAVIANI, D. Competência política e compromisso técnico (ou o pomo da discórdia e o fruto proibido). Educação \& Sociedade, São Paulo, n. 15, p. 111-143, ago. 1983.

. Escola e democracia ou a teoria da curvatura da vara. ANDE, São Paulo, n. 1, p. 23-33, 1981a. $\overline{56-64,1982 .}$

Escola e democracia: para além da curvatura da vara. ANDE, São Paulo, n. 3, p.

Extensão universitária: uma abordagem não-extensionista. Educação \& Sociedade, São Paulo, n. 8, p. 61-73, jan. 1981b.

SILVA JUNIOR, C. A. A supervisão e o ensino. ANDE, São Paulo, n. 3, p. 39-40, 1982.

A UNIVERSIDADE brasileira e a relação com o projeto de desenvolvimento. ANDE, São Paulo, n. 2, p. 23-29, 1981.

VEIGA, L. da. Os projetos educativos como projetos de classe: Estado e universidade no Brasil (1954-1964). Educação \& Sociedade, São Paulo, n. 11, p. 25-71, jan. 1982.

Gilson R. de M. Pereira, doutor em educação pela Faculdade de Educação da Universidade de São Paulo (USP), é professor do Programa de Pós-Graduação, Mestrado em Educação, da Universidade Regional de Blumenau (Furb).

gilsonmp@furb.br 


\section{Abstract}

From analysis of articles published in specialized periodicals, the research investigates the forms assumed by politization from the Brazilian educational field during the years of 1978 to 1986. Politization, manifestation of an intensely heteronomous status of the educational field, as characterized during the period by the ambiguous alliance between educators and workers, transfiguration almost unrecognizable of the structural affinities between occupying agents of the dominated poles both from the academic field and from the general social space.

Keywords: educational field; autonomy; heteronomy; politization; structural affinities.

Recebido em 3 de abril de 2003.

Aprovado em 20 de outubro de 2003. 